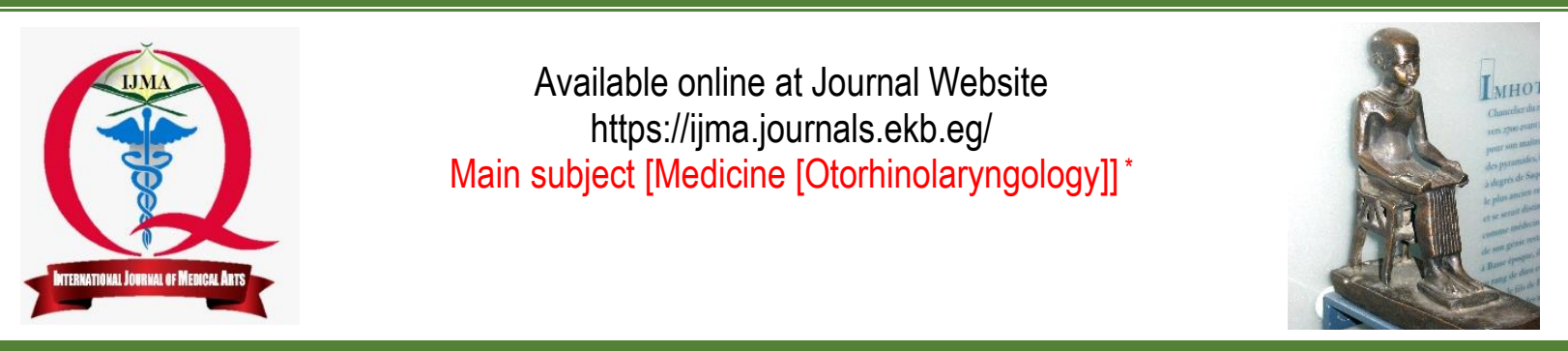

Original article

\title{
Comparative Study between Intranasal Injection of Botulinum Toxin-A and Combined Intranasal Medical Treatment for Allergic Rhinitis
}

\author{
Nabil Abdelghany Sarhan[a]; Mohamed Fathallah[b]; Ashraf Abdalla Wahba [a]; Ahmed Alwan[c]
}

Department of Otorhinolaryngology, Damietta Faculty of Medicine, Al-Azhar University, Egypt [a].

Department of Otorhinolaryngology, Faculty of Medicine, Al-Azhar University, Egypt ${ }^{[b]}$

Department of Clinical Pathology, Damietta Faculty of Medicine, Al-Azhar University, Egypt[c]

Corresponding author: Nabil Abdelghany Sarhan

Email: nabelent@yahoo.com

Received at: March 29, 2020; Revised at: June 16, 2020; Accepted at: June 22, 2020; Available online at: June 22, 2020

DOI: 10.21608/IJMA.2020.26878.1113

\begin{abstract}
Background: Allergic rhinitis is one of the most common diseases, with no consensus on its ideal treatment. Botulinum ToxinA was proposed to be an effective treatment.

Aim of the work: To estimate the outcome of intranasal injection of Botulinum Toxin-A [BTX-A] as a sole therapy for allergic rhinitis.

Patients and Methods: Ninty patients with classic symptoms of allergic rhinitis were clinically evaluated and asked to complete the score for allergic rhinitis [SFAR] questionnaire using cutoff at $>8$ as diagnostic AR. Two blood samples [venous] and nasal smears were obtained at the beginning of the study and at the end of 12-weeks after initiation of therapy for estimation of human immunoglobulin $E[\mathrm{lgE}]$ and eosinophilia grading. Control group included patients who chose to receive combined medical treatment. BTX-A, 2.5 units were injected intranasally, under 00 rigid telescope guidance. Study outcome was the treatment success rate at the end of 12-w follow-up period.
\end{abstract}

Results: Intranasal BTX-A injection provided significantly maintained relieve of allergic rhinitis manifestations especially for running nose than combination therapy. The treatment success rate of 1.9 versus 0.7 item/patient in study versus control group with significant difference in favor of BTX-A injection. Serum lgE levels and eosinophilia grades were significantly lower in control patients. Patients' satisfaction grading was significantly more with BTX-A injection.

Conclusion: Intranasal BTX injection could be a safe and effective sole therapeutic modality for patients with long-lasting AR.

Keywords: Allergic Rhinitis; Botulinum Toxin-A; Intranasal Injection; Medical Treatment; Score for Allergic Rhinitis.

This is an open access article under the Creative Commons license [CC BY] [https://creativecommons.org/licenses/by/2.0/]

Please cite this article as: Sarhan NA, Fathallah M, Wahba AA, Alwan A. Comparative Study between Intranasal Injection of Botulinum Toxin-A and Combined Intranasal Medical Treatment for Allergic Rhinitis. IJMA 2020; 2[3]: 590-598.

* Main subject and any subcategories have been classified according to the research topic. 


\section{INTRODUCTION}

Rhinitis is characterized by nasal congestion, rhinorrhea, sneezing, and/or posterior nasal drainage ${ }^{[1] .}$.

Rhinitis affects a significant portion of the population with a significant impact on their quality of life and presents a large burden economically [2].

Rhinitis is broadly characterized as allergic and non-allergic, and the latter may be divided according to the etiological cause into inflammatory and noninflammatory [3].

Allergic rhinitis is a common condition with increasing prevalence ${ }^{[4]}$.

It was considered as localized disorder affecting the nose and nasal passages ${ }^{[5]}$, however current evidence indicates that it may represent a component of a systemic airway disease involving the entire respiratory tract [6] and is frequently associated with several comorbid disorders such as bronchial asthma, allergic conjunctivitis ${ }^{[7]}$ and atopic dermatitis [4].

Symptoms of rhinitis are attributed to nasal hyperreactivity which is defined as increased sensitivity of nasal mucosal effector nerves, blood vessels, and glands to triggering factors ${ }^{[8]}$ and its magnitude depends on both the type and quantity of sensory input and reflects the degree of nasal reactivity[9].

Nasal hyper-reactivity occurs in association with increased sensitivity of sensory nerves, afferent parasympathetic signals ${ }^{[10]}$ and number or sensitivity of receptors on effector cells in blood vessels and glands with decreased sympathetic balance for increased parasympathetic signals [11] and changed modulation of afferent impulses from central nervous system [12].

Current pharmacologic options include oral and intranasal antihistamines, decongestants, anticholinergics, intranasal corticosteroids and leukotriene receptor antagonists[13].

Combination therapy with decongestants and first-generation antihistamines can be considered if monotherapy does not adequately control symptoms ${ }^{[14]}$.

Practice guidelines recommended intranasal corticosteroids as first-line treatment for moderate to severe allergic rhinitis[ ${ }^{[13]}$, however combined second generation antihistamines and intranasal steroids are safe and effective treatments[15].

Botulinum neurotoxin [BoNT], the most poisonous known substance is synthesized as a progenitor toxin complex by Clostridium botulinum ${ }^{[16]}$.

BoNT exists as seven serotypes [A-G] differ between $35-68 \%$ in amino acid sequence [17].

BoNT is one of the most powerful inhibitors for acetylcholine release from nerve endings ${ }^{[18]}$.

Considering the best therapeutic regimen is that provide symptomatic relief and better quality of life ${ }^{[19]}$.

\section{AIM OF THE WORK}

The current study tried to evaluate the outcome of intranasal injection of Botulinum Toxin-A [BTX$A]$ as a sole therapeutic line for patients with rhinitis.

\section{PATIENTS AND METHODS}

\section{Study Design:}

Prospective clinical intervention

\section{Study Setting:}

Departments of Otorhinolaryng-ology and Clinical Pathology, Yanbu National Hospital, Kingdom of Saudi Arabia [KSA]

\section{Patients and Methodology:}

The current study was conducted since Jan 2018, after approval of the study protocol by the Local Ethical Committee. All patients presented with any of the classic symptoms of rhinitis; nasal congestion, nasal itching, sneezing, rhinorrhea, and/or posterior nasal drainage ${ }^{[1,5]}$ were eligible for evaluation.

Clinically, all patients were asked to complete the SFAR questionnaire [Score for allergic rhinitis] which covers the presence and/or severity of 8 features of $\mathrm{AR}$ during the last 12-m duration, each of these features was scored by $0-2$ for a maximum score of 16 [20]. The SFAR cutoff at $>8$ was used for diagnosis of $A R$ as it was previously documented by Ologe et al. [21] to have sensitivity and specificity rate of $94.8 \%$ and $95.1 \%$ for identification of $A R$ cases and correlated with nasal smear eosinophil count.

At preliminary evaluation, the full SFAR score was determined and only patients with SFAR score $>8$ were chosen for enrolment in the study and then 
the last three items of SFAR score; namely, the presence of previous medical diagnosis, positive tests and family history of allergy were excluded off the score depending on their stability during followup, and the maximum score for comparison during follow-up was considered 11 points.

All patients underwent clinical examination of the upper respiratory tract, and endoscopic nasal examination to evaluate the nasal mucosa, presence of secretion, associated sinusitis, turbinate hypertrophy, or nasal polypi. Then, a blood sample and nasal smear specimens were obtained.

Exclusion criteria included failure to respond correctly to the structured questionnaire, maintenance on antihistamine or other anti-allergy medications, previous surgical interventions involved the nose and paranasal sinuses, or presence of nasal polyp or picture suggestive of nasal and paranasal sinus malignancies on endoscopic examination. Also, patients who refused to participate in the study were excluded.

\section{Sampling \& Investigations:}

Two venous blood samples and nasal smears were obtained prior to start of treatment and at end of 12-w follow-up after initiation of therapy.

a. Blood sampling \& investigations: Venous blood samples [5 ml] were collected from the antecubital vein under complete aseptic conditions, kept in a plane container and allowed to clot then serum was separated by centrifugation at 3000 rpm for 10 min. Serum was removed and placed in pyrogen-free Eppendorf tubes and stored at $-70^{\circ} \mathrm{C}$ till be assayed for serum human immunoglobulin $E$ [lgE] by enzyme linked immunosorbent assay [ELISA] kit [catalog no. ab108650; Abcam, Cambridge, USA] by sandwich enzyme linked immunosorbent assay technology according to manufacture instructions [22].

b. Nasal smearing: nasal smear specimen was obtained using disposable sterile nasal probe, one for each nasal cavity as previously described by Rakesh et al. [23]. Briefly, the nasal probe was run along the medial surface of the inferior turbinate 2-3 times and the obtained specimen was smeared on a clear glass slide, one for each nostril, air dried and fixed with 95\% alcohol immediately. Then, the slides were stained using Giemsa stain and examined microscopically. Nasal smear eosinophilia was graded according to Abhey [24] as Normal [+1] on presence of $<10$ cells/highpower field [HPF] or eosinophilia $<5 \%$ of HPF, Mild [+2] on presence of 10-30 cells/HPF or eosinophilia $>5 \%$ of HPF, Moderate [+3] on presence of numerous cells, not covering the entire microscopic field or eosinophilia about $50 \%$ of HPF and Marked [+4] on the presence of numerous cells, covering the entire microscopic field or eosinophilia $>50 \%$ of HPF

\section{Grouping:}

Management regimens were discussed with patients eligible for inclusion and those chose the conventional regimen consisted of intranasal corticosteroid and decongestant with oral antihistaminic drugs were included as control group, and patients accepted to receive intranasal injection of Botulinum toxin type A [BTX-A] were grouped as Study group.

\section{Injection Procedure:}

Botulinum toxin A [Botox Allergan, Dublin, Ireland] $100 \mathrm{U}$ was reconstituted with $4 \mathrm{ml}$ of normal saline to reach a final concentration of 25 units $/ \mathrm{ml}$. Using sterile disposable 31-gauge syringe of $1 \mathrm{ml}$ size, $0.1 \mathrm{ml}$ of fluid containing 2.5 units of Botox was injected in the middle turbinate anterior region and the inferior turbinate medial region under $0^{\circ}$ rigid telescope guidance after application of xylocaine spray [local anesthetic]. Then, patients were asked not to use any medication before notification of the authors.

\section{Study Outcomes:}

1. Primary outcome is the treatment success rate that was defined as number of patients who stopped to complain of at least one of SFAR items at the end of 12-w follow-up period.

2. Secondary outcomes included

a. Number of patients had improved SFAR items in both groups during the two weekly observations till 12-w follow-up period 
b. Mean SFAR score at each follow-up visit

c. Change of serum $\lg E$ and eosinophilia grading at end of followup in comparison to Pre-treatment levels

d. Patients' satisfaction by the outcome graded on 5-point Likert scale including 5 items; very satisfying, satisfying, good, dissatisfying, poor outcome.

\section{Sample size calculation:}

Previously, Zicari et al.[25] reported significant difference in nasal scores of $30 \mathrm{AR}$ patients/group on treatment using combined corticosteroid and saline versus saline only, while Gao et al. [26] reported nonsignificant difference of nasal scores of 93 AR patients/group on treatment using combined corticosteroid and antihistaminic therapy versus corticosteroid with saline.

Considering the SFAR at $>8$ as diagnostic cutoff point for AR, the current study suggested good outcome indicated decreased SFAR score by $50 \%$ [22] and a sample size of 41 AR patients/ group can allow to detect a $>50 \%$ difference of SFAR score between patients received Botox injection and combined corticosteroid and antihistaminic therapy and to achieve study power of $85 \%$ with a value of $5 \%$ and $\beta$ value of $15 \%$.

To guard against exclusion or missing of some cases during follow-up, the study was designed to include 45 patients per group.

\section{Statistical analysis:}

Obtained data were presented as mean $\pm S D$, numbers and percentages. Results were analyzed using paired t-test, One-way ANOVA Test and Chisquare test $\left[\mathrm{X}^{2}\right.$ test]. Statistical analysis was conducted using the IBM SPSS [Version 23, 2015; IBM, South Wacker Drive, Chicago, USA] for Windows statistical package. $\mathrm{P}$ value $<0.05$ was considered statistically significant.

\section{RESULTS}

The study included 117 rhinitis patients; 27 patients were excluded for not fulfilling the inclusion criteria and 90 patients were divided into two equal groups [Figure 1].

There was non-significant difference between patients of both groups regarding the inclusion criteria as shown in table [1].

All items of SFAR score were improved in patients of both groups till the end of 12-w follow-up. For both therapeutic modalities the effect was more evident at 4-w and was more pronounced with intranasal BTX injection that induced significantly lower number of patients still complaining of various SFAR items in comparison to combined medical therapy received by control patients. Interestingly, intranasal injection significantly reduced number of patients complaining of running nose till end of follow-up in comparison to control group.

Considering therapeutic success as number of patients free of complaining of even one of SFAR items at end of follow-up; success rate was 1.9 versus 0.7 item/patient in study and control groups, respectively. However, the effect of intranasal injection was more pronounced on running nose with significant $[\mathrm{p}=0.0012]$ difference between both groups. Mean numerical scoring of patients of study group was significantly lower than control patients since 4-w till end of follow-up [Table 2, Figure 2].

At end of 12-w follow-up serum lgE levels and eosinophilia grades were significantly $[p=0.016$ \& 0.0345 , respectively] lower in control patients, but non-significantly lower in study patients in comparison to their pre-treatment levels with nonsignificant differences between both groups despite being in favor of control group [Table 3].

Forty-eight patients [53.4\%] found outcome was very satisfying-to-satisfying, 21 patients [23.3\%] found it good and 21 patients [23.3\%] found outcome was dissatisfying-to-poor with significantly $[\mathrm{p}=0.026]$ higher frequency of patients found outcome very satisfying-to-satisfying in study than in control group [Fig. 3]. 
Sarhan NA, et al.

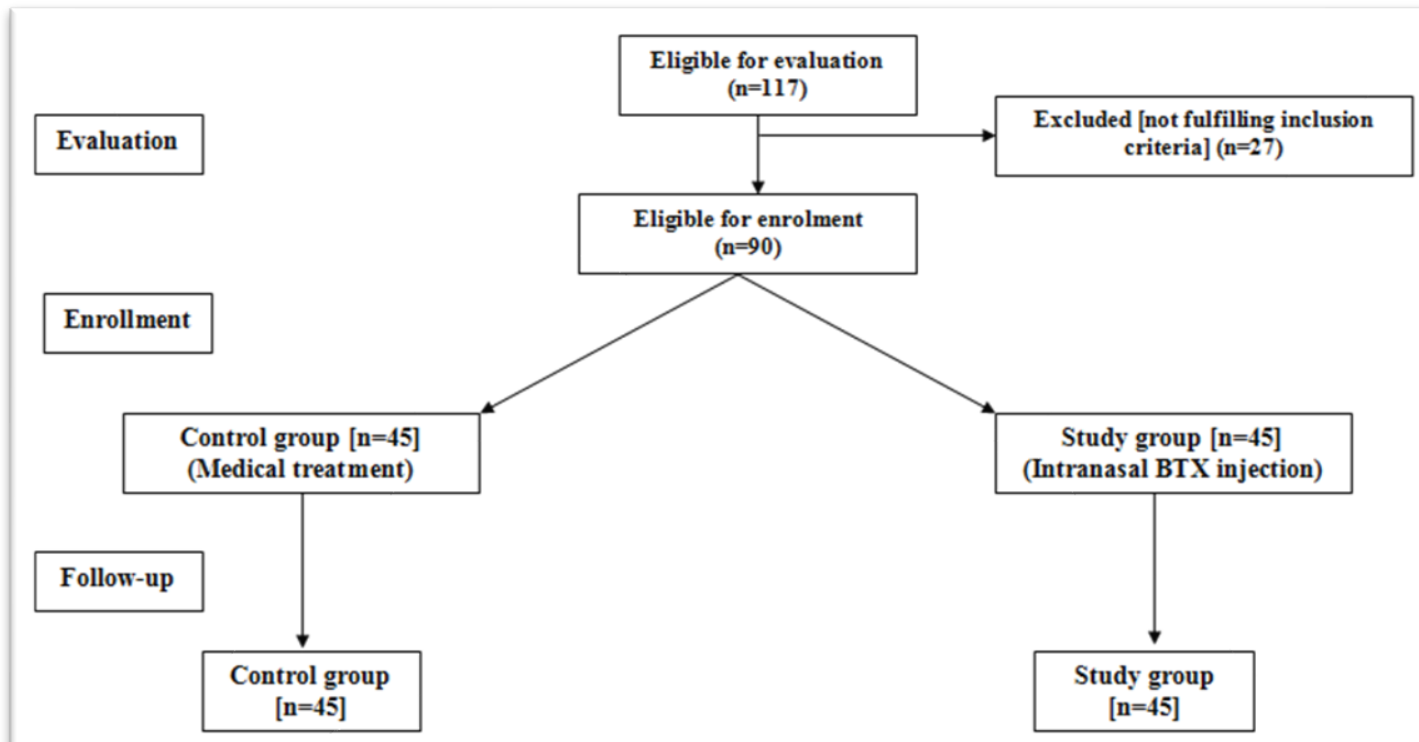

Figure 1: Consort Flow sheet

Table [1]: Criteria of patients of both groups

\begin{tabular}{|c|c|c|c|c|}
\hline \multicolumn{2}{|l|}{ Data } & Control group [n=45] & Study group [n=45] & $P$ value \\
\hline \multicolumn{2}{|l|}{ Age [years] } & $31 \pm 8.1$ & $32.8 \pm 7$ & 0.262 \\
\hline \multicolumn{2}{|l|}{ Weight [kg] } & $86 \pm 6.4$ & $87.4 \pm 7.7$ & 0.349 \\
\hline \multicolumn{2}{|l|}{ Height $[\mathrm{cm}]$} & $169.4 \pm 3.9$ & $169.8 \pm 4$ & 0.562 \\
\hline \multicolumn{2}{|c|}{ Body mass index $\left[\mathrm{kg} / \mathrm{m}^{2}\right]$} & $30 \pm 2.1$ & $30.3 \pm 2.3$ & 0.618 \\
\hline \multicolumn{2}{|c|}{ Serum lgE [IU/ml] } & $217.3 \pm 86.9$ & $186.5 \pm 115.4$ & 0.156 \\
\hline \multirow{3}{*}{$\begin{array}{l}\text { Eosinophilia } \\
\text { grade }\end{array}$} & Mild [+2] & $8[17.8 \%]$ & $10[22.2 \%]$ & \multirow{3}{*}{0.553} \\
\hline & Moderate [+3] & $26[57.8 \%]$ & $28[62.2 \%]$ & \\
\hline & Severe $[+4]$ & $11[24.4 \%]$ & $7[15.6 \%]$ & \\
\hline
\end{tabular}

Data are presented as mean $\pm S D$, number \& percentage; $P$ indicates significance of difference between control \& study groups; $P>0.05$ indicates non-significant difference

Table [2]: Patients' distribution among items of SFAR score and mean of SFAR score at each follow-up visit in both groups

\begin{tabular}{|c|c|c|c|c|c|c|c|c|c|c|c|c|c|c|c|c|c|}
\hline \multirow[b]{2}{*}{ Data } & \multirow{2}{*}{$\begin{array}{l}\text { Time } \\
\text { Group }\end{array}$} & \multicolumn{2}{|c|}{ Pre-treatment } & \multicolumn{2}{|c|}{$2-w$} & \multicolumn{2}{|c|}{ 4-w } & \multicolumn{2}{|c|}{ 6-w } & \multicolumn{2}{|c|}{ 8-w } & \multicolumn{2}{|c|}{ 10-w } & \multicolumn{2}{|c|}{ 12-w } & \multicolumn{2}{|c|}{ Success rate } \\
\hline & & c & s & C & $\mathrm{s}$ & C & $s$ & c & $\mathrm{s}$ & c & s & c & s & c & s & C & s \\
\hline \multirow[b]{2}{*}{ Nasal block } & Number & 38 & 39 & 31 & 26 & 27 & 14 & 23 & 15 & 25 & 21 & 29 & 23 & 32 & 27 & $6[13.3 \%]$ & $12[26.7 \%]$ \\
\hline & $P$ value & \multicolumn{2}{|c|}{0.764} & \multicolumn{2}{|c|}{0.274} & \multicolumn{2}{|c|}{0.006} & \multicolumn{2}{|c|}{0.088} & \multicolumn{2}{|c|}{0.399} & 0 & & \multicolumn{2}{|c|}{0.267} & \multicolumn{2}{|c|}{0.114} \\
\hline \multirow[b]{2}{*}{ Runny nose } & Number & 39 & 42 & 33 & 27 & 25 & 12 & & 16 & 30 & 19 & & 22 & 35 & 25 & $4[8.9 \%]$ & $17[37.8 \%]$ \\
\hline & $P$ value & \multicolumn{2}{|c|}{0.191} & \multicolumn{2}{|c|}{0.179} & \multicolumn{2}{|c|}{0.005} & \multicolumn{2}{|c|}{0.011} & \multicolumn{2}{|c|}{0.021} & \multicolumn{2}{|c|}{0.017} & \multicolumn{2}{|c|}{0.025} & \multicolumn{2}{|c|}{0.0012} \\
\hline \multirow[b]{2}{*}{ Sneezing } & Number & 36 & 38 & 26 & 23 & 30 & 9 & & 13 & 25 & 20 & & 25 & & 30 & $7[15.6 \%]$ & $8[17.8 \%]$ \\
\hline & $P$ value & \multicolumn{2}{|c|}{0.581} & \multicolumn{2}{|c|}{0.525} & & 001 & & & & & 0. & & & & & \\
\hline & Number & 33 & 38 & 28 & 29 & 28 & 18 & & 20 & 24 & 22 & & 25 & & 28 & $4[8.9 \%]$ & $10[22.2 \%]$ \\
\hline Seasonal/perennial & $P$ value & & & & & & & & & & & & & & & & \\
\hline & Number & 34 & 33 & 24 & 26 & & 17 & & 18 & 25 & 24 & 27 & 26 & 31 & 27 & $3[6.7 \%]$ & $6[13.3 \%]$ \\
\hline Rhino-conjunctivitis & $P$ value & & & & & & 33 & & & & & & & & & & \\
\hline & House & 9 & 12 & 8 & 9 & 9 & 5 & 6 & 5 & 7 & 6 & & 8 & 9 & 8 & 0 & $4[8.9 \%]$ \\
\hline Triggering allergen & & & & & & & 45 & & & & & 0.7 & & & & & \\
\hline & Pollen & 13 & 18 & 11 & 10 & & 6 & 9 & 7 & 11 & 10 & 13 & 11 & & 11 & 0 & $7[15.6 \%]$ \\
\hline & & & & & & & 71 & & & & & 0. & & & & & \\
\hline Allergic status & Number & 34 & 37 & 28 & 27 & & 17 & & 19 & 28 & 22 & & 25 & 32 & 28 & $2[4.4 \%]$ & $9[20 \%]$ \\
\hline & $P$ value & & & & & & & & & & & 0.2 & & & & & \\
\hline Mean SFAR score & Control & & & $5.8=$ & & & & & & & & $5.9=$ & & & & & \\
\hline & Study & & & $5.6=$ & & $3.1=$ & $0.8^{*}$ & & & & & $5.1=$ & & 5.7 & & & \\
\hline & $P$ value & & & & & $<0.0$ & 0001 & & & & & & & & & & \\
\hline
\end{tabular}

Data are presented as number, mean $\pm S D$, percentage; C: control group; S: Study group; $\mathrm{P}$ indicates significance of difference between control \& study groups;

* indicates significance of difference versus pre-treatment score; $P<0.05$ indicates significant difference; $P>0.05$ indicates non-significant difference 


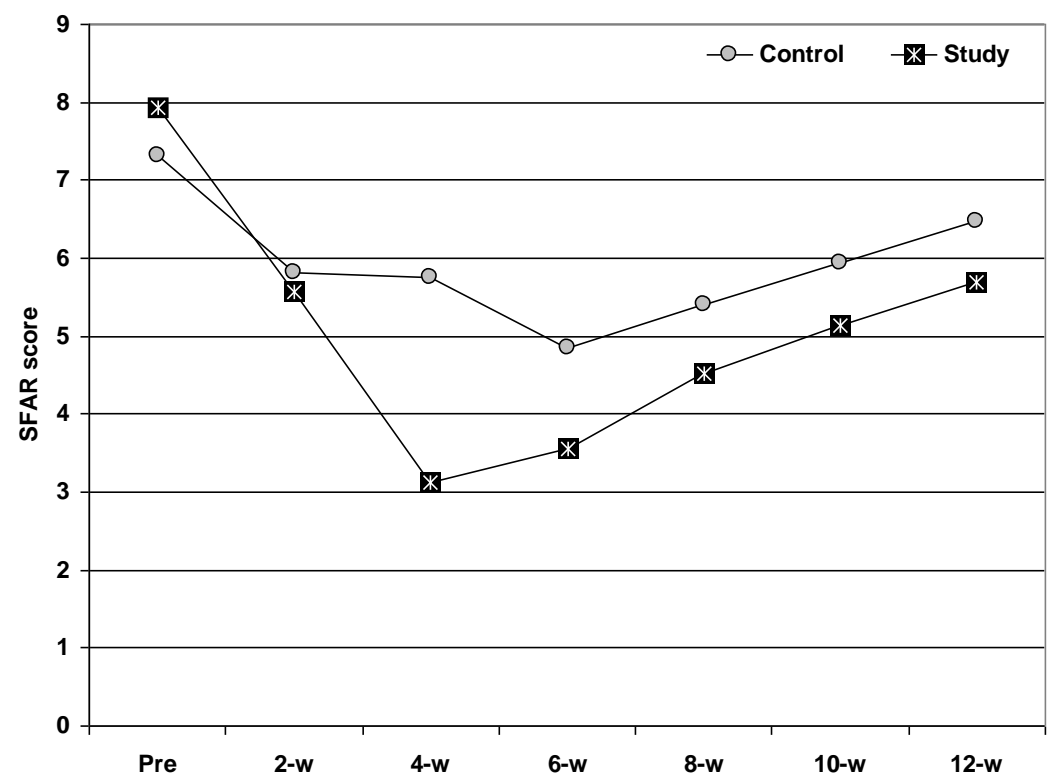

Fig. (2): Mean SFAR score of patients of both groups throughout 12w observation period

Table [3]: Pre- and Post-treatment laboratory findings of patients of both groups

\begin{tabular}{|c|c|c|c|c|c|}
\hline & & & Control & study & P1 value \\
\hline \multirow{3}{*}{ Serum lgE [IU/ml] } & \multicolumn{2}{|l|}{ Pre-intervention } & $217.3 \pm 86.9$ & $186.5 \pm 115.4$ & 0.156 \\
\hline & \multicolumn{2}{|l|}{ Post-intervention } & $173.6 \pm 81.8$ & $147.1 \pm 87.7$ & 0.143 \\
\hline & \multicolumn{2}{|l|}{ P2 value } & 0.016 & 0.071 & \\
\hline \multirow{7}{*}{ Eosinophilia grade } & \multirow{3}{*}{ Pre-intervention } & Mild [+2] & $8[17.8 \%]$ & $10[22.2 \%]$ & \multirow{3}{*}{0.553} \\
\hline & & Moderate [+3] & $26[57.8 \%]$ & $28[62.2 \%]$ & \\
\hline & & Severe $[+4]$ & $11[24.4 \%]$ & $7[15.6 \%]$ & \\
\hline & \multirow{3}{*}{ Post-intervention } & Mild [+2] & $19[42.2 \%]$ & $20[44.4 \%]$ & \multirow{3}{*}{0.799} \\
\hline & & Moderate [+3] & $20[44.4 \%]$ & $21[46.7 \%]$ & \\
\hline & & Severe $[+4]$ & $6[13.3 \%]$ & $4[8.9 \%]$ & \\
\hline & & & 0.0345 & 0.076 & \\
\hline
\end{tabular}

Data are presented as mean $\pm S D$, number \& percentage; $P 1$ indicates significance of difference between control \& study; $P 2$ indicates significance of difference between pre- \& post-treatment value; $P<0.05$ indicates significant difference; $P>0.05$ indicates non-significant difference

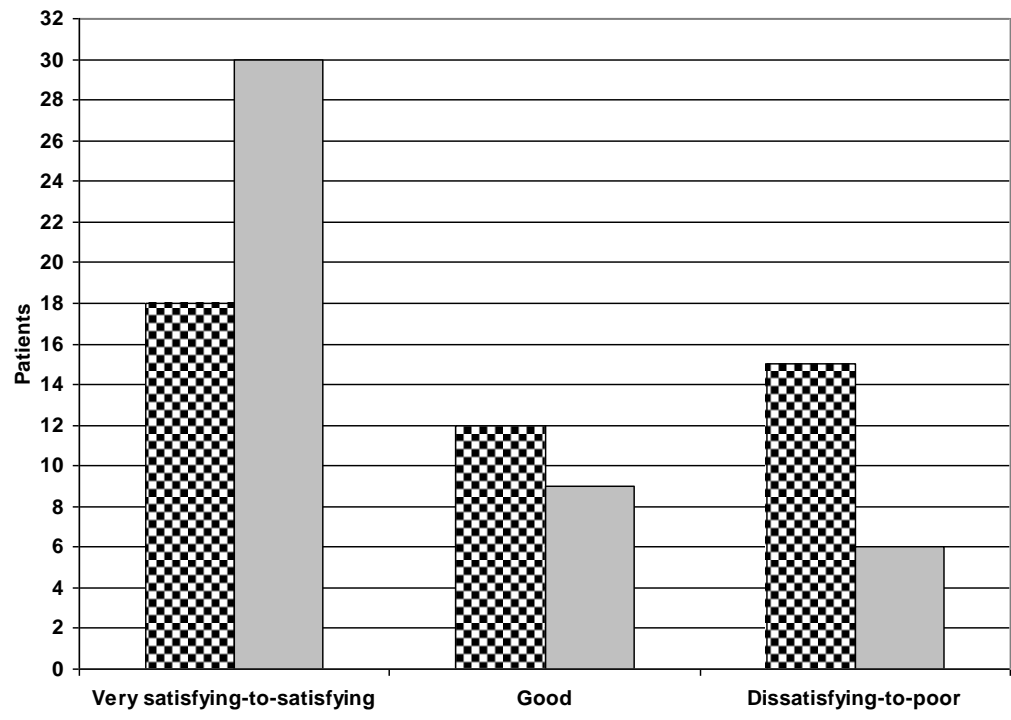

Fig. (3): Patients' distribution according to their satisfaction by 


\section{DISUCSSION}

Both therapeutic modalities were beneficial and allowed alleviation of manifestations of $A R$ as manifested by the significantly lower SFAR during 12-w follow-up period in comparison to their baseline SFAR score. However, intranasal botulinum toxin [BTX] injection provided maintained relieve of AR manifestations especially for running nose with significant difference compared to control group during the follow-up period. Moreover, at end of follow-up 17 patients had no running nose, 12 patients had no blocked nose and 7 patients had no seasonal or perennial attacks during this period of follow-up after injection with resolution of 1.9 item/patient [success rate]. On contrary, among control patients the success rate was 0.7 item/patient with significantly higher success rate with intranasal BTX injection.

These findings point to the higher efficacy of intranasal BTX injection than medical therapy and to its durability as a sole line of AR therapy that spared the need for additional medical therapies. These results go in hand with the early studies tried BTX injection in lower and middle nasal concha of patients with intrinsic rhinitis [27] or submucoperichondrial injection of BTX in nasal septum of patients with idiopathic rhinitis ${ }^{[28]}$ and reported that BTX injection could achieve good symptom control and patient comfort [28] with full effect appearing within 1-2 weeks after application and lasted for 8-12 weeks [27]. Also, Abtahi et al. [29] found both septal and turbinal BTA injections effectively reduced total symptom severity score and severity of sneezing, rhinorrhea, and congestion in both groups of $A R$ patients with non-difference between both groups

In a similar comparative study, Hashemi et al. [30] comparing the effects of BTX injection and cetirizine on AR symptoms and found total symptom severity score of patients significantly decreased and quality of life significantly improved at the same level in both groups, but with more side effects with cetirizine. Also, Mozafarinia et al.[31] documented that submucoperichondrial BTX injection can be considered as an effective therapeutic option in patients with persistent AR and idiopathic rhinitis.

Moreover, the obtained results are in line Ozcan and Ismi[32] who documented that intranasal BTX administration is safe and effective treatment for decreasing rhinitis symptoms in rhinitis patients with a long-lasting effect and appears to be good treatment option for chronic rhinitis patients who are resistant to other treatment methods. Also, Zhang et al. [33] who showed significant improvement of Total Nasal Symptom Score of AR patients after BTX intranasal injection compared to pre-injection score with the greatest effect was in rhinorrhea, sneeze, nasal congestion and itch subscales and significant improvement in all domains of quality of life scoring, so concluded that BTX shows clear efficacy on symptoms of both intrinsic and allergic rhinitis, with a good safety profile, and duration of action. Thereafter, Zand et al. [34] reported significant symptomatic relieve that was maintained for at least 8 weeks using gel-foam impregnated with BTX in AR patients who were non-responder to common therapies and concluded that this therapeutic regimen is an effective and safe. Recently, Xu and Chen ${ }^{[3]}$ documented that the potential application of BTX in treating rhinitis has been confirmed both in clinical practice and previous studies.

Multiple previous animal studies were conducted to determine the clinical and histological effect of BTX on nasal mucosa, Aoishi et al. [36] using single intranasal BTX infusion in mice model of AR reported significantly decreased nasal serous discharge and sneezing with decreased capillary dilatation and eosinophil infiltration by Day 3 after infusion without change in number and size of nasal mucosal secretary glands and Güneş et al. [37] found BTX infiltration in the inferior turbinates of rabbit model of resulted in decreased nasal discharge, scratching and blockage and reorganization of histopathological findings of AR with significant difference between disease and treatment groups.

Other experimental studies tried to explore the underlying mechanism for the reported beneficial effect of BTX on clinical and histopathological manifestations of AR, where Liu et al.[38] using rat model of AR attributed improvement of AR symptoms by BTX dripping to inhibition of the expression of vasoactive intestinal peptide and pituitary adenylate cyclase activating polypeptide in nasal mucosa. Recently, Xu \& Chen [35] documented that the target of BTX-A is to selectively cleave the synaptosome-associated protein of $25 \mathrm{KD}$ molecular mass, so inhibits the release of neurotransmitter and causes chemodenervation. 
Conclusion: Intranasal BTX injection could be a safe and effective sole therapeutic modality for patients with long-lasting AR. Also, BTX injection provided long-lasting effect and spared the need for adjunct medical therapy and this can compensate for its cost, which limits its routine use. However, wider scale studies are mandatory to establish these results and comparative studies were needed to define the dose-duration of action relationship.

\section{Financial and Non-Financial Relationships and Activities of Interest}

None declared by the authors

\section{REFERENCES}

1. Beard S. Rhinitis. Prim Care. 2014; 41[1]:33-46. [DOI: 10.1016/j.pop.2013.10.005].

2. May JR, Dolen WK. Management of Allergic Rhinitis: A Review for the Community Pharmacist. Clin Ther. 2017; 39[12]:2410-2419. [DOI: 10.1016/j.clinthera.2017.10.006].

3. Agnihotri NT, McGrath KG. Allergic and nonallergic rhinitis. Allergy Asthma Proc. 2019 Nov 1;40[6]:376-379. [DOI: 10.2500/aap.2019.40.4251].

4. Klimek L, Sperl A, Becker S, Mösges R, Tomazic PV. Current therapeutical strategies for allergic rhinitis. Expert Opin Pharmacother. 2019 Jan;20[1]:83-89. [DOI: 10. 1080/ 14656566.2018.1543401].

5. Small P, Keith PK, Kim H. Allergic rhinitis. Allergy Asthma Clin Immunol. 2018; 14[Suppl 2]:51. doi: 10.1186/s13223-018-0280-7.

6. Wise SK, Lin SY, Toskala E. International consensus statement on allergy and rhinology: allergic rhinitisexecutive summary. Int Forum Allergy Rhinol. 2018; 8[2]:85-107. [DOI: 10.1002/alr.22070].

7. Mehta R. Allergy and Asthma: Allergic Rhinitis and Allergic Conjunctivitis. FP Essent. 2018; 472:11-15. [PMID: 30152668].

8. Segboer CL, Holland CT, Reinartz SM, Terreehorst I, Gevorgyan A, Hellings PW, van Drunen CM, Fokkens WJ. Nasal hyper-reactivity is a common feature in both allergic and nonallergic rhinitis. Allergy 2013; 68[11]:1427-34. [DOI: 10.1111/all.12255].

9. Eguiluz-Gracia I, Pérez-Sánchez N, Bogas G, Campo P, Rondón C. How to Diagnose and Treat Local Allergic Rhinitis: A Challenge for Clinicians. J Clin Med. 2019; 8[7]. pii: E1062. [DOI: 10.3390/jcm8071062].

10. Hom MM, Bielory $L$. The anatomical and functional relationship between allergic conjunctivitis and allergic rhinitis. Allergy Rhinol [Providence]. 2013; 4[3]:e110-9. [DOI: 10.2500/ar.2013.4.0067].

11. Jaradeh SS, Smith TL, Torrico L, Prieto TE, Loehrl TA, Darling RJ, Toohill RJ. Autonomic nervous system evaluation of patients with vasomotor rhinitis. Laryngo- scope 2000; 110 [11]: 1828-31. [DOI: 10.1097/ 00005537 200011000-00012]

12. Kim D, Baraniuk JN. Neural aspects of allergic rhinitis. Curr Opin Otolaryngol Head Neck Surg. 2007; 15[4]:26873. [DOI: 10.1097/MOO.0b013e328259c372].

13. Greiwe JC, Bernstein JA. Combination therapy in allergic rhinitis: What works and what does not work. Am J Rhinol Allergy. 2016; 30[6]:391-396. [DOl: 10.2500/ajra.2016.30.4391].

14. Sur DKC, Plesa M. Chronic Nonallergic Rhinitis. Am Fam Physician. 2018; 98[3]:171-176. [PMID: 30215894].

15. Powell-Dunford N, Reese C, Bushby A, Munkeby BH, Coste S, Pezer VL, Rosenkvist L. The Aeromedical Management of Allergic Rhinitis. Aerosp Med Hum Perform. 2018; 89[5]:453-463. [DOI: 10.3357/ AMHP. 4867.2018].

16. Kutschenko A, Bigalke $H$, Wegner $F$, Wohlfarth $K$. The role of human serum albumin and neurotoxin associated proteins in the formulation of BoNT/A products. Toxicon. 2019; 168:158-163. [DOI: 10.1016/j.toxicon. 2019.07.005].

17. Snow DM, Riling K, Kimbler A, Espinoza Y, Wong D, Pham K, et al. Safety and Pharmacokinetics of a Four Monoclonal Antibody Combination Against Botulinum C and D Neurotoxins. Antimicrob Agents Chemother. 2019 Oct 7. pii: AAC.01270-19. [DOI: 10.1128/AAC.01270-19].

18. Cariati M, Chiarello MM, Cannistra' M, Lerose MA, Brisinda G. Gastrointestinal uses of Botulinum Toxin. Handb Exp Pharmacol. 2020 Feb 19. [DOl: 10.1007/164_2019_326]. [Epub ahead of print]

19. Greiwe J, Bernstein JA. Nonallergic Rhinitis: Diagnosis. Immunol Allergy Clin North Am. 2016; 36[2]:289-303. [DOI: 10.1016/j.iac.2015.12.006].

20. Annesi-Maesano I, Didier A, Klossek M, Chanal I, Moreau D, Bousquet J. The score for allergic rhinitis [SFAR]: a simple and valid assessment method in population studies. Allergy 2002; 57[2]:107-14. [DOl: 10.1034/j.1398-9995.2002. 103170.x].

21. Ologe FE, Adebola SO, Dunmade AD, Adeniji KA, Oyejola BA. Symptom score for allergic rhinitis. Otolaryngol Head Neck Surg. 2013; 148[4]:557-63. [DOI: 10.1177/0194599813477605].

22. Wang N, Li J, Huang $X$, Chen W, Chen Y. Herbal Medicine Cordyceps sinensis Improves Health-Related Quality of Life in Moderate-to-Severe Asthma. Evid Based Complement Alternat Med. 2016;2016: 6134593. [DOI: 10.1155/2016/6134593].

23. Rakesh C, Aggarwal AK, Kohli GS, Jaswal TS, Gupta KB. Comparative study of nasal smear and biopsy in patients with allergic rhinitis. Indian J Allergy Asthma Immunol. 2002;16: 27-31.

24. Abhey S. Diagnostic significance of nasal eosinophilia in allergic rhinitis. Indian J Otolaryngol Head Neck Surg. 2005; 57:13-16. [DOI: 10.1007/BF02907618]. 
25. Zicari AM, Occasi F, Montanari G, Indinnimeo L, De Castro G, Tancredi G, Duse M. Intranasal budesonide in children affected by persistent allergic rhinitis and its effect on nasal patency and Nasal Obstruction Symptom Evaluation [NOSE] score. Curr Med Res Opin. 2015; 31[3]:391-6. [DOI: 10.1185/03007995.2015.1009532].

26. Gao XP, Zhou Y, Feng NY, Hou L, Yang J, Yong H, Ma RX. Curative observation on allergic rhinitis treated by intranasal corticosteroids combined with nasal irrigation. Lin Chung Er Bi Yan Hou Tou Jing Wai Ke Za Zhi. 2016; 30 [9]: 702-706;711. [DOI: 10.13201/j.issn.1001-1781. 2016.09.008].

27. Nowak K, Szyfter W. Application of botulinum toxin A in chronic intrinsic rhinitis. Otolaryngol Pol. 2011 MarApr;65[2]:103-5. [DOI: 10.1016/S0030-6657[11]70637-0].

28. Braun T, Gürkov R, Kramer MF, Krause E. Septal injection of botulinum neurotoxin A for idiopathic rhinitis: a pilot study. Am J Otolaryngol. 2012; 33[1]:64-7. [DOI: 10.1016/j.amjoto. 2011.01.004].

29. Abtahi SM, Hashemi SM Abtahi SH, Bastani B. Septal injection in comparison with inferior turbinates injection of botulinum toxin $A$ in patients with allergic rhinitis. J Res Med Sci. 2013; 18[5]:400-4. [PMID: 24174945].

30. Hashemi SM, Okhovat A Amini S, Pourghasemian M. Comparing the effects of Botulinum Toxin-A and cetirizine on the treatment of allergic rhinitis. Allergol Int. 2013; 62 [2]: 245-9. [DOI: 10.2332/ allergolint.12-OA-0510].

31. Mozafarinia K, Abna M, Khanjani N. Effect of Botulinum Neurotoxin A Injection into the Submucoperichondrium of the Nasal Septum in Reducing Idiopathic Non-Allergic Rhinitis and Persistent Allergic Rhinitis. Iran J Otorhinolaryngol. 2015; 27[81]:253-9. [PMID: 26788472].

32. Ozcan C, Ismi O. Botulinum Toxin for Rhinitis. Curr Allergy Asthma Rep. 2016; 16[8]:58. [DOI: 10.1007/ s11882-016-0636-3].
33. Zhang EZ, Tan S, Loh I. Botolinum toxin in rhinitis: Literature review and posterior nasal injection in allergic rhinitis. Laryngoscope. 2017; 127[11]:2447-2454. [DOI: 10.1002/lary.26616].

34. Zand V, Baradaranfar M, Dadgarnia M, Meybodian M, Vaziribozorg S, Mandegari M, Behniafard N, Dehghani A. The Effect of Gelfoam Impregnated with Botulinum Toxin on Allergic Rhinitis. Iran J Otorhinolaryngol. 2019; 31 [105]: 203-208. [PMID: 31384585].

35. Xu YL, Chen JH. Application status and prospect of botulinum toxin $\mathrm{A}$ in otorhinolaryngological treatment. Lin Chung Er Bi Yan Hou Tou Jing Wai Ke Za Zhi. 2020 Jan;34[1]:88-91. [DOI: 10.13201/j.issn.1001-1781. 2020. 01. 022].

36. Aoishi K, Takahashi H, Hato N, Gyo K, Yokota M, Ozaki S, Suzuki M. Treatment of allergic rhinitis with intranasal infusion of botulinum toxin type $A$ in mice. Life Sci. 2016; 147:132-6. [DOI: 10.1016/j.Ifs.2015.08.003].

37. Güneş MS, Külahlı I, Kökoğlu K, Vural A, Avcı $D$, Güleç $S$, et al. Evaluation of the effect of intranasal infiltrated botulinum toxin-A on a model of allergic rhinitis in rabbits: An Experimental Study. Int J Pediatr Otorhinolaryngol. 2016; 83:51-6. [DOI: 10.1016/j.jporl. 2016. 01. 010].

38. Liu L, Wang B, Liang G, Lu L, Yang L. [Experimental studies for botulinum toxin type $A$ to antagonist the VIP/PACAP expression on nasal mucosa in allergic rhinitis rat]. Lin Chung $\mathrm{Er} \mathrm{Bi}$ Yan Hou Tou Jing Wai Ke Za Zhi. 2016; 30 [1]: 49-53. Article in Chinese [English Abstract] [PMID: 27197456]. 